\title{
Editorial
}

\section{Preface to the special issue on the European Hydrogen Energy Conference 2018, EHEC2018, Malaga, Spain}

Since 2005, the European Hydrogen Energy Conferences (EHECs) have provided an international interdisciplinary forum devoted to hydrogen and related technologies. EHEC2018 was held in Malaga, Spain from 14th to 16th March 2018. It was organized by the Spanish Hydrogen Association with the support and collaboration of the European Hydrogen Association, Hydrogen Europe, the International Hydrogen Energy Association, the International Journal of Hydrogen Energy and Hydrogen Europe Research.

EHEC2018 was a great success as the main goals of an EHEC were fully accomplished: dissemination and promotion of the use of hydrogen technologies; sharing of the new research and business advances with society; presentation and discussion of the most innovative research in hydrogen and fuel cell technologies; and encouragement of the exchange of scientific and technical information between the different actors in the $\mathrm{H}_{2}$-related sector. Some 400 participants from 34 countries attended EHEC2018 and contributed to its success.

Plenary presentations at the conference addressed representative developments in: fuel cell electric vehicles and hydrogen infrastructures; $\mathrm{H}_{2}$ and fuel cell national initiatives, strategies and legislation; and new hydrogen opportunities and challenges. A total of 150 oral presentations in 6 parallel sessions, together with 100 poster communications covered the main topics in the field of hydrogen, fuel cells and the related technologies. There were specific sessions devoted to economic and environmental aspects, public strategies and the presentation of European projects.

For this Special Issue devoted to EHEC2018, 31 papers have been accepted of 43 manuscripts submitted by authors responsible for the oral presentations at the conference. It covers the main aspects of hydrogen and fuel cell technologies and satisfactorily reflects the diversity of contributions to EHEC2018. Several papers deal with advances in the catalysts and electrocatalysts used for $\mathrm{H}_{2}$ production from renewable and non-renewable substrates. Some authors also address hydrogen purification processes and progress in $\mathrm{H}_{2}$-storage, including molecular simulations. Different papers cover fuel cell systems, including reaction mechanisms, industrial production of electrodes, modelling, components, degradation and applications in the stationary or transportation sectors. Finally, it includes papers that deal with the analysis of technical and economic aspects of hydrogen-based energy systems, public strategies and environmental impact.

As the guest editors of this Special Issue, we would like to thank all the authors for their contributions and also the reviewers and editors of the International Journal of Hydrogen Energy for their efficient assistance. We hope that all our readers will enjoy this selection of papers and profit from what they read.

Pilar Ramírez de la Piscina* Departament de Química Inorgànica i Orgànica, Secció de Química Inorgànica and Institut de Nanociència i Nanotecnologia, Universitat de Barcelona, C/ Martí i Franquès 1-11, 08028, Barcelona,

Spain

Félix Barreras

LIFTEC, CSIC-Univ. of Zaragoza, C/ María de Luna, 10, 50018,

Zaragoza, Spain

Vanesa Gil

Fundación para el Desarrollo de las Nuevas Tecnologías del Hidrógeno en Aragón, PT. Walqa. Ctra. N330A km 566, 22197,

Huesca, Spain

ARAID Foundation, Auda. de Ranillas 1D, 50018 Zaragoza, Spain

Elena Pastor

Instituto Universitario de Materiales y Nanotecnología, Dpto de Química, Po. Box 456, 38200, La Laguna, Tenerife, Spain

*Corresponding author. E-mail address: pilar.piscina@qi.ub.es (P. Ramírez de la Piscina)

Available online $\mathrm{xxx}$

https://doi.org/10.1016/j.ijhydene.2019.03.152 0360-3199/@ 2019 Hydrogen Energy Publications LLC. Published by Elsevier Ltd. All rights reserved. 